\title{
MIGRAÇÕES ULTRAMARINAS. TRABALHADORES BRASILEIROS NO JAPÃO
}

\author{
ALICE YATIYO ASARI \\ REIMEI YOSHIOKA
}

\begin{abstract}
ASARI, A.Y.; YOSHIOKA, R. Migrações ultramarinas. Trabalhadores brasileiros no Japão.
Semina: Ci. Sociais/Humanas, Londrina, v. 17, n. 3, p. 237-245, set. 1996.

RESUMO: O artigo analisa a dinâmica migratória, especificamente, o fluxo de trabalhadores brasileiros, de origem japonesa, para o Japão. Este fluxo de trabalhadores iniciou-se no final da década de 1980, estimando-se em 170 mil brasileiros no Japão, como trabalhadores não especializados. Os movimentos populacionais são movidos por interesses econômicos, sociais e políticos dos países, tornando os migrantes "homens do mundo" que se movem aos sabores das necessidades de mão-de-obra de países desenvolvidos e subdesenvolvidos.
\end{abstract}

PALAVRAS-CHAVE: Dinâmica migratória; trabalhadores brasileiros; migrações temporárias

\section{Introdução}

Que razões levam o homem a deixar seu lugar, sua pátria e aventurar-se em terras desconhecidas, muitas vezes extremamente distantes? Como se dá a sua inserção nestas terras, no novo mundo por ele recriado?

São estas as indagações que motivaram a elaboração do presente artigo, que visa, através da análise dos deslocamentos populacionais, refletir sobre a questão migratória. Qualquer mudança é profundamente penosa, visto que surgem, para os que emigram, problemas decorrentes da adaptação ao novo meio, do mesmo modo que a região que recebe esse contingente populacional também sofrerá mudanças, pela presença dos recém-chegados.

Outro ponto a ser considerado é que o sujeito do deslocamento vive duas situações distintas, pois, como emigrante, ele sofre profundas rupturas com suas raízes e vínculos sócio-espaciais e, como imigrante, ele entra em rota de colisão com sistemas de valores diferenciados, aos quais se espera a sua adaptação. Desta forma, deduz-se que o imigrante enfrentará dificuldades no tocante à sua inserção numa sociedade que possui valores diferentes, com sistemas sócioeconômicos a serem internalizados e com isso terá de buscar a sua estabilidade, administrando suas diferenças, acomodando, assimilando o que a sociedade receptora lhe apresenta.

Há que se considerar ainda que a história da humanidade registra desde os seus primórdios, o deslocamento de homens sobre a superfície terrestre, ora em busca de ambiente mais propício sob o ponto de vista climático, ora fugindo da escassez de alimentos ou para afastar-se de inimigos naturais mais poderosos, entre inúmeras outras causas. A estes fatores, cabe referenciar Singer (1977:40-41,77) que discorre sobre um outro motivador de deslocamentos:

"São os fatores de atração que determinam a orientação destes fluxos e as áreas às quais se destinam. Entre os fatores de atração, o mais importante é a demanda por força de trabalho, entendida esta não apenas como a gerada pelas empresas industriais mas também a que resulta da expansão de serviços, tanto dos que são executados por empresas capitalistas como os que são prestados por repartições governamentais, empresas públicas e por indivíduos autônomos. (...) De uma forma geral, interpreta-se esta demanda por força de trabalho como proporcionando oportunidades econômicas, que constituem um fator de atração na medida em que oferecem uma remuneração mais elevada que a que o migrante poderia perceber na área de onde provém".

É possivel enquadrar como típicos desta migração, os atuais "dekasseguis", que se dirigem para o Japão atendendo à demanda de mão-de-obra não especializada

'Departamento de Geociências, Centro de Ciências Exatas/Universiade Estadual de Londrina (PR).

${ }^{2}$ Centro de Informação e Apoio ao Trabalhador no Exterior - CIATE. São Paulo (SP). 
nas indústrias automobilística e eletroeletrônica, na construção civil e nas empresas de prestação de serviços.

Este movimento de trabalhadores para o Japão é condizente com a informação de Yamochi (1992) que, segundo a Organização Internacional do Trabalho (OIT), deverá haver um intenso fluxo migratório de países pobres para países ricos. Há que se lembrar ainda que, por estas mesmas razões, cerca de 40 milhões de pessoas deixaram a Europa, no século XIX, em direção aos países do continente americano. O total de todos os europeus que deixaram seus países de origem até o início da II Guerra Mundial alcança 70 milhões de pessoas.

Santos (1994:40-41) coloca que "após a Segunda Guerra Mundial, há tendência à inversão das correntes migratórias graças, em grande parte, à prosperidade renovada nos países ricos, cujos habitantes desdenham as tarefas consideradas mais humildes, pesadas ou degradantes". É ainda relevante considerar que o tipo de migração vivenciada atualmente, por descendentes de japoneses ("nikkeis") está vinculada ao que George (1978) denomina de "migrações temporárias", a qual apresenta-se como uma solução para o problema imediato de emprego, "quando o empregador (...) não deseja encarregar-se da instalação e da manutenção social de um excesso de população correspondente à necessidade da força de trabalho". Neste caso, são alvo dessa "migração de trabalhadores temporários" pessoas cuja força de trabalho se acha no seu apogeu e que devem permanecer no local durante um pequeno número de anos. "A sua substituição efetua-se mediante a troca de contingente ou até de pessoas. Nesse caso não há migrações de população, mas apenas migração de trabalhadores e, essencialmente, migração de homens dos 18 aos 30 anos". (George, 1978:104-105)

Acrescente-se ainda que, "em todos os casos de emigração, uma das poucas vantagens dos imigrantes, frente aos naturais do país, é que, nos primeiros tempos, quando predomina a idéia de uma migração temporária, o migrante está disposto a aceitar qualquer tipo de trabalho, muitas vezes fazendo coisas que não aceitaria fazer em seu próprio país". (Klagsbrunn, 1995:6)

Esta é uma faceta do processo migratório que leva a reflexões sobre o papel do Estado nos destinos dos seus cidadãos. Indagações são então levantadas como: Qual a função do Estado ? Que tipo de pressão exerce o capital sobre a força de trabalho? Quais os mecanismos para atrair a força de trabalho, regular a sua produção, manter em níveis adequados o "exército industrial de reserva"? Que papéis desempenham os governos? Qual a relação entre o capital e o governo? Nesse processo, o Estado perde a chance de atuar como uma entidade que assegura a justiça social, barrando os abusos cometidos pelas grandes corporações. Note-se que essas migrações vêm se constituindo numa saída para os trabalhadores de países em desenvolvimento que não encontram empregos, em razão das características estruturais do capitalismo, ou então dos "deserdados" deste tipo de economia. A forma desordenada, clandestina como ocorrem, somada à reação negativa e defensiva dos países de destino, tem gerado grandes problemas econômicos, étnicos e políticos.

Um outro ponto de vista é apresentado por Santos (1980:179-180), ao assegurar que

"...os grandes movimentos de homens são uma outra característica do mundo atual, que não podem sercontrolados, guiados, orientados pelo Estado. Estas trocas multiplicadas, que são o comum da economia internacional de hoje, dão ao Estado um papel no qual ele não pode ser substituído. Mesmo as grandes firmas têm de recorrer ao Estadopara defender alguns ou muitos de seus interesses. É por isso que o Estado é levado a ampliar cada dia seu papele a intrometer-secadavez mais em diversos domínios anteriormente reservados às iniciativas privadas".

Estas considerações evidenciam a necessidade de refletir sobre o papel exercido pelos que detém o poder político neste momento em que os países são envolvidos por condições inerentes ao período tecnocientífico vigente, em que se sobressaem, além dos movimentos migratórios internacionais, uma economia mundializada, globalizada, uma política internacional fundada em interesses econômicos, uma insatisfação progressiva das populações que vivem em condições precárias ou então desconhecimento do potencial de seus recursos naturais.

De outra forma, de que maneira a comunidade a que pertence o imigrante reage a esta ausência temporária de seus pares? E na nova comunidade que os recebe ? Quais as implicações no seio de sua família? E no indivíduo? São de Martins (1988:49-50), as reflexões sobre presença/ausência, sobre a ambigüidade do viver do imigrante:

"Se em termos demográficos, a duração - o temporário - é essencial para o estudo das migrações temporárias, em termos sociológicos o essencial é a concepção de ausência. É temporário, na verdade, aquele imigrante que se considera a si mesmo "fora de casa", "fora do lugar", ausente, mesmo quando, em termos demográficos, tenha migrado definitivamente. $\dot{E}$ aquele que se considera fora do seu lugar, fora de suas relações sociais, e que, no limite, não 
se considera dentro, mesmo quando está. Se ausência é o núcleo da consciência do migrante temporário, é porque ele não cumpriu e não encerrou o processo de migração, com seus dois momentos extremos e excludentes: a dessocialização, nas relações sociais de origem, e a ressocialização, nas relações sociais de "adoção". Ele se mantém, pois, na duplicidade de suas socializações, de duas estruturas de relações sociais diversas entresi. Ele vive a marginalidade de duas situações sociais".

Cabe então fazer referência ao processo de mobilização social, relacionada a dinâmica migratória, em que são analisadas as variáveis psicológicas, pois esta temporalidade do ir e vir faz do migrante um indivíduo que vive dois mundos diferentes, e não tem seu lugar em nenhum deles. Assim, grande parte desses homens do trabalho vivencia uma situação singular em que são movidos pelos tentáculos do capital urbano-industrial, locomovendo-se onde encontrar empresas que comprem sua mão-de-obra por períodos em que sua força de trabalho é necessária, ou que ainda não foi "sucateada".

\section{Os movimentos migratórios internacionais em função do trabalho}

Nos dias atuais ocorre um intenso fluxo de pessoas entre países. No entanto, a qualidade deste deslocamento é pouco conhecida, pois as estatísticas oficiais rotulam os que chegam ou deixam o país de turistas, tornando as informações a respeito das migrações pouco confiáveis, dispersas e contraditórias. Este fluxo de pessoas decorre da necessidade de buscar melhores condições de vida, pois em seus países de origem não conseguem os meios necessários para sua sobrevivência. Portanto, evidencia-se uma situação em que ocorre um deslocamento de trabalhadores, na sua maioria, temporários.

Estes movimentos migratórios representam, segundo informações contidas no relatório das Nações Unidas (1993), uma importante fonte de divisas, pois estima-se em 70 bilhões de dólares o total remetido aos seus países de origem, fruto do seu trabalho. Este relatório conclui ainda que o trabalho remunerado dos migrantes fora de seus países de origem constitui-se na segunda maior "indústria"do mundo (apenas o petróleo a supera).

No que se refere ao Brasil, estas estimativas apresentavam dados os mais diversos, de tal forma que o Ministério das Relações Exteriores realizou o $1^{\circ}$ censo da emigração, concluído em março/96, conforme relata Klintowitz, na Revista Veja de 03.04.96. Segundo esta publicação, existem 1.500 .000 brasileiros no exterior, enviando de volta quatro bilhões de dólares ao ano. São 33 os países onde há comunidades com mais de 1.000 brasileiros, que os escolheram como local de trabalho. O Japão, com os "dekasseguis", constitui-se no país que ocupa o $3^{\circ}$ lugar de preferência dos brasileiros, com 170.000 pessoas, antecedido apenas pelos Estados Unidos e Paraguai. A figura 01, "Brasileiros no Exterior", melhor visualiza este fato.

FIGURA 01 - Brasileiros no exterior

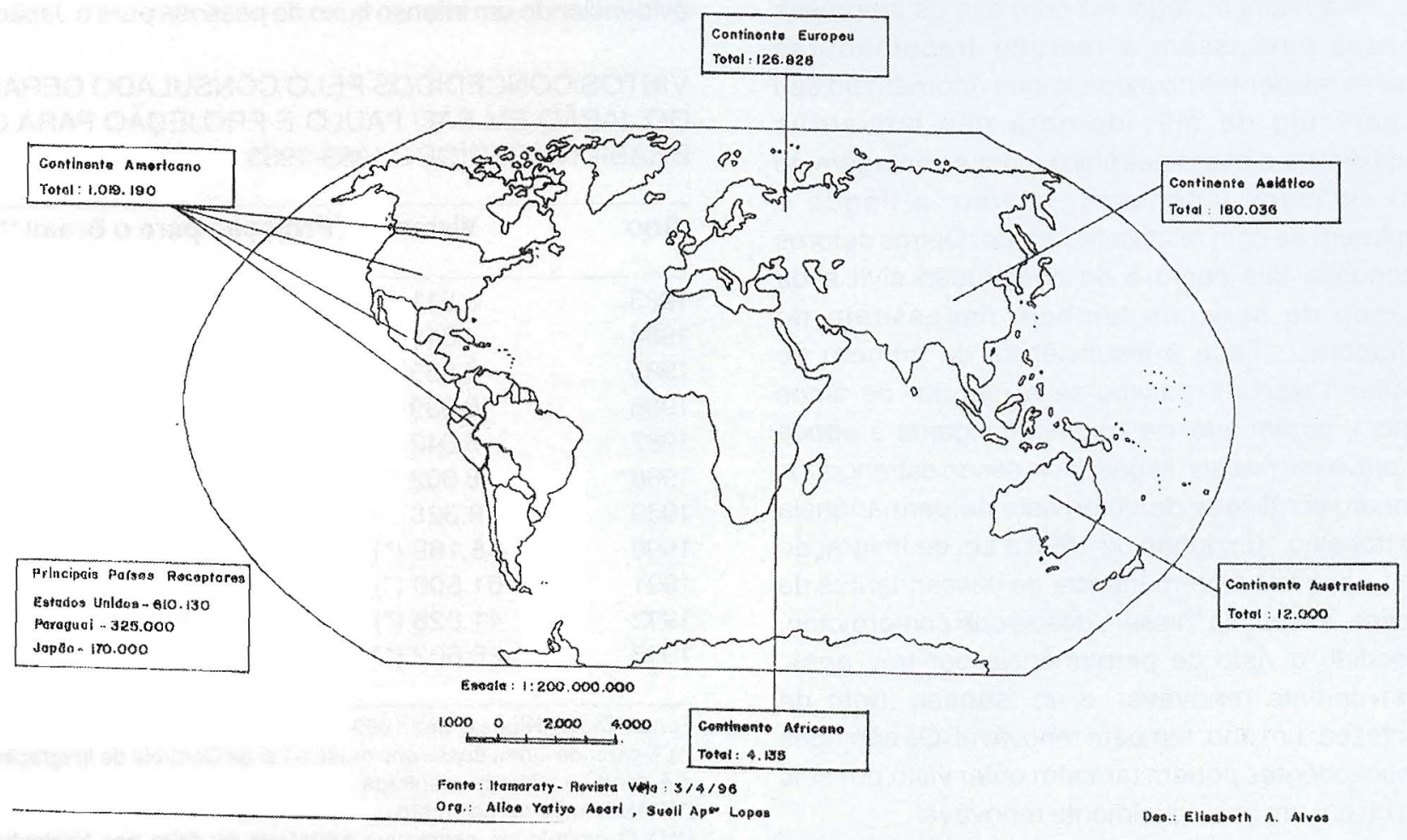


03. Dekasseguis brasileiros no mercado de trabalho japonês

Os imigrantes japoneses, aqueles que estão na faixa dos 70-80 anos, estão presenciando a despedida de filhos, netos ou bisnetos, que se dirigem para o Japão, na qualidade de trabalhadores temporários, para executar as atividades não especializadas em empresas japonesas.

Este fluxo em direção ao Oriente mostra o caráter dinâmico do processo migratório, pois, passados mais de oito décadas do início da imigração japonesa para o Brasil, este movimento de pessoas tem sido objeto de reportagens dos meios de comunicação, de debates em simpósios realizados por instituições que se dedicam aos estudos populacionais e as questões que envolvem sua comunidade.

A nivel de Brasil, este deslocamento "dekassegui"- tem sido maior nos últimos dez anos e decorre, essencialmente, das condições econômicas críticas do nosso país, aliada a possibilidade de conseguir ganhos substanciais em um curto espaço de tempo no exterior. "Dekassegui"é a palavra japonesa que significa aquele que vai trabalhar fora (de, raiz do verbo deru, que quer dizer sair; kassegui, significa trabalho remunerado). No Brasil este vocábulo tem sentido pejorativo e significa "ir trabalhar num país estrangeiro", segundo o jornal "Paraná Shimbum"(1990).

Note-se ainda que milhares de asiáticos invadiram o mercado de trabalho japonês, atraídos pelos altos salários, sendo empregados ilegalmente, como clandestinos, visto que a lei de imigração não lhes reconhecem o direito de permanência para trabalhar no Japão. Esta restrição legal fez com que as empresas japonesas passassem a recrutar trabalhadores japoneses residentes no exterior, que retornam ao seu país servindo de mão-de-obra nas indústrias automobilística e eletroeletrônica, com a vantagem de serem cidadãos japoneses, falarem a língua e readaptarem-se com relativa facilidade. Outros setores da economia tais como a da construção civil e da prestação de serviços também necessitam de trabalhadores. Face à insuficiência do número de japoneses ("isseis"), passou-se a recrutar os filhos ("nisseis"), porém a lei de imigração vigente à época considerava os "nisseis" ilegais, pois sendo estrangeiros não tinham condições de obter visto de permanência para o trabalho. Em junho de 1990 a Lei de Imigração facilitou a entrada e permanência de descendentes de japoneses. Assim, ao "nissei", desde que comprovado, é concedido o visto de permanência por três anos, sucessivamente renovável, e ao "sansei: (neto de imigrante) por um ano, também renovável. Os cônjuges não descendentes podem também obter visto por seis meses ou por um ano, igualmente renovável.

Esta situação possibilita fazer reflexões sobre o processo de migração como um todo, principalmente no que se refere a condição dupla de "vencidos"e "marginalizados", tanto no Brasil como no Japão. Assim, o "retorno"ao Japão, na qualidade de trabalhadores temporários, mostra a realidade então vivenciada, pois os imigrantes japoneses vieram para o Brasil em razão das dificuldades existentes em seu país e o país receptor mostrava-se com enormes potencialidades; ao chegar ao Brasil, passaram por fases de adaptação, muitas vezes dolorosas, buscando a sua inserção na sociedade que os recebera. No momento em que consideravam ter sua vida (econômica, social, cultural) estabilizada, ou então, com evidências de uma significativa adaptação ao país (Brasil), estes migrantes são envolvidos por outra "onda" migratória, esta em sentido inverso, como se fosse um "retorno"ao país que os havia liberado décadas atrás. Porém, este "retorno"não se dá nas condições desejadas pelos "velhos imigrantes", uma vez que, no Japão estes "dekasseguis" trabalharão em atividades não especializadas e desgastantes. Isto mostra a condição de "vencidos" no Brasil, porque necessitam "voltar"ao país dos seus pais e avós para lá conseguir acumular algum capital, embora "marginalizados". Lá, farão parte de um contingente de mão-de-obra que ocupa funções não aceitas pelos naturais do país, que não tem domínio da língua japonesa, possuem costumes diferenciados e principalmente, não são japoneses.

Os dados sobre o total de vistos concedidos pelo Consulado Geral do Japão em São Paulo e projeção para o Brasil, no período 1983-1993, são apresentados a seguir, à guisa de ilustração; tais informações permitem verificar que a partir de 1989 há um crescimento significativo do total de vistos concedidos, evidenciando um intenso fluxo de pessoas para o Japão.

VISTOS CONCEDIDOS PELO CONSULADO GERAL DO JAPÃO EM SÃO PAULO E PROJEÇÃO PARA O BRASIL NO PERÍODO 1983-1993.

\begin{tabular}{lcc}
\hline Ano & Vistos & Projeção para o Brasil ${ }^{\star \star \star}$ \\
\hline 1983 & 3.811 & 5.445 \\
1984 & 4.311 & 6.159 \\
1985 & 6.553 & 9.361 \\
1986 & 6.639 & 9.484 \\
1987 & 5.842 & 8.346 \\
1988 & 8.602 & 12.189 \\
1989 & 18.328 & 26.183 \\
1990 & $48.189\left(^{\star}\right)$ & 68.841 \\
1991 & $61.500\left(^{\star}\right)$ & 87.858 \\
1992 & $41.828\left(^{\star}\right)$ & 59.754 \\
1993 & $26.603\left(^{\star \star}\right)$ & $38.004\left(^{\star \star}\right)$
\end{tabular}

Fonte: Diário Nippak, dez.1993

(*) A partir de junho desse ano muda a Lei de Controle de Imigração e é criado o visto de reentrada.

$\left({ }^{\star \star}\right)$ Até o mês de setembro

${ }^{* * *}$ ) O cálculo da estimativa projetada foi feita por Yoshioka (1995:89)

Semina Ci. Sociais/Hum., v. 17, n. 3, p. 237-245 
Um outro dado importante para a análise do fluxo de trabalhadores brasileiros para o Japão é o que consta do Registro de Estrangeiros, do Ministério da Justiça do Japão, na Seção de Imigração, o qual apresenta os dados cumulativos e semestrais acerca dos naturais do Brasil, Peru, Argentina, Paraguai e Bolívia. Verificase que em cinco anos, o número de estrangeiros dos países nominados tem um acréscimo de cerca de $100 \%$, pois de 110.000 passa para 210.000 pessoas, sendo que o Brasil comparece com $80 \%$, seguido do Peru com $17 \%$ do total de estrangeiros. Estes dados, aliado ao fato de que ambos os países contam com expressivo contingente de imigrantes japoneses, dá a dimensão dos deslocamentos de seus filhos e netos em direção ao Japão, na qualidade de trabalhadores temporários. (Fig. 02)

Quanto aos "dekasseguis" brasileiros, verificase que a maioria está distribuída nas regiões metropolitanas de Tóquio, Osaka e Nagóia, que são as que concentram as indústrias e as empresas prestadoras de serviços. Em 1995, dos 168.662 brasileiros registrados no Ministério da Justiça Japonesa, na Seção de Imigração, as quatro províncias que abrigavam maior número pessoas egressas do Brasil eram:

\section{Províncias total/pessoas \% de participação}

$\begin{array}{lrr}\text { - Aichi ........ } & 28.898 & 17,13 \% \\ \text { - Shizuoka..... } & 24.249 & 14,38 \% \\ \text { - Kanagawa .. } & 13.795 & 8,18 \% \\ \text { - Saitama....... } & 10.305 & 6,12 \%\end{array}$

Ressalte-se que estas quatro províncias englobam $45 \%$ dos brasileiros que se encontravam no Japão à época do levantamento, deduzindo-se que estão prestando serviços nas empresas industriais localizadas nas regiões de maior dinamismo econômico do país.

FIGURA 02 - Registro de estrangeiros de acordo com os países

\begin{tabular}{lrrrrrrrrr}
\hline Países & $1991 / 1$ & $1991 / 2$ & $1992 / 1$ & $1992 / 2$ & $1993 / 1$ & $1993 / 2$ & $1994 / 1$ & $1994 / 2$ & $1995 / 1$ \\
\hline Brasil & 88201 & 119333 & 139072 & 147803 & 155714 & 154650 & 154762 & 159619 & 168662 \\
Peru & 17350 & 26281 & 30886 & 31051 & 33233 & 33169 & 34088 & 35382 & 36111 \\
Argentina & 3105 & 3366 & 3331 & 3289 & 3199 & 2934 & 2860 & 2796 & 2846 \\
Paraguai & 900 & 1052 & 1188 & 1174 & 1166 & 1080 & 1130 & 1129 & 1181 \\
Bolívia & 1021 & 1766 & 2265 & 2387 & 2652 & 2932 & 2994 & 2917 & 2796 \\
\hline Total & 110577 & 151798 & 176742 & 185704 & 195964 & 194765 & 195834 & 201843 & 211596 \\
\hline
\end{tabular}

Fonte: Ministério da Justiça - Seção de Imigração - Japão. 1995.

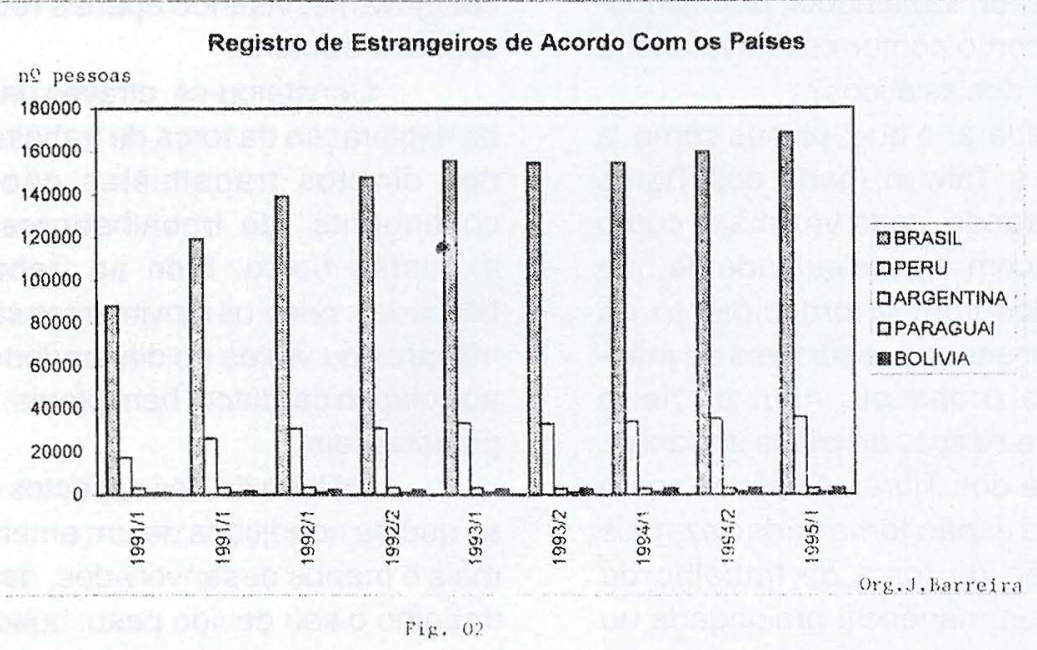

\section{Reflexões acerca do fenômeno dekassegui}

O fluxo de japoneses e seus descendentes para trabalhar, temporariamente, no Japão, enseja a necessidade de se fazer levantamentos sistemáticos, estudos sobre tal fenômeno, analisando-se todas as facetas, quer seja por uma equipe interdisciplinar ou não, para que as propostas apresentadas advindas de pesquisas consolidadas, minimizem os problemas decorrentes desta "aventura além-mar".

O estudo que envolve os "dekasseguis" é um exemplo do deslocamento de pessoas para fins de 
trabalho, e peculiar, por se tratar de descendentes de japoneses que outrora emigraram para diversos quadrantes do mundo e hoje são chamados de volta para suprir de mão-de-obra a indústria japonesa, as empresas de prestação de serviços e também as atividades ligadas ao setor primário da economia.

Entretanto, apesar dessa ocorrência se dar entre japoneses e seus descendentes, como acentuam os discursos governamentais, a realidade observada é a exploração da força de trabalho pelo capital urbanoindustrial.

Os trabalhadores são vendidos aos intermediários que, por sua vez, repassam-nos ao setor produtivo para serem espoliados ao máximo. Quando de sua exaustão são devolvidos ao país de origem , que os criou e lhes deu a formação necessária para ingressarem no mercado de trabalho. Constata-se então que o investimento em educação apresenta-se altamente oneroso para a nação, penalizando duplamente países que não tem condições de ofertar aos seus jovens condições satisfatórias de emprego e salário.

O Japão, graças a inúmeras circunstâncias, atingiu um alto nivel de desenvolvimento, mas, por outro lado, a política demográfica reduziu consideravelmente a entrada de jovens nesse mesmo mercado, sobretudo no trabalho não-especializado. A população envelhecida é cada vez mais dependente, não de alta tecnologia, mas de trabalhadores que os ajudem a preencherem o tempo cada vez maior de ociosidade.

Ademais, a brusca oscilação no mercado de exportação da indústria automobilística e eletroeletrônica obrigou as empresas a recorrerem à força de trabalho não disponível no país. Os países asiáticos, pela sua proximidade geográfica, são os potenciais fornecedores dessa mão-de-obra, no entanto, o problema reside na questão da admissão legal do trabalhador, permitindoIhe fixar-se no Japão. E como conter essa avalanche de entrada indiscriminada dos asiáticos?

Outro fato a considerar é que, países como a China, a Coréia do Sul e Taiwan (parte dos Tigres Asiáticos), estão se mostrando, cada vez mais, como potenciais concorrentes, com a peculiaridade de que estes foram beneficiados com o fornecimento de tecnologia, exatamente por serem possuidores de mãode-obra "barata", o que propiciou, num primeiro momento, parceria para a realização ampliada do capital. No entanto, a emergência dos Tigres Asiáticos como possíveis concorrentes do Japão torna cada vez mais problemática a introdução da força de trabalho de asiáticos, com status de permanência prolongada ou definitiva. Assim, a alternativa de recrutar os "nikkeis" foi estratégica, por conta do parentesco com os japoneses.

Portanto, os trabalhadores brasileiros no Japão são atraídos pelas ofertas das agenciadoras e representantes das empresas japonesas, as quais vêem nos descendentes de japoneses, trabalhadores potencialmente mais propensos à adaptação ao trabalho, aos costumes e conseqüentemente, com um mínimo de problemas a serem enfrentados durante a permanência no país. Verificou-se, igualmente, que no Brasil, a maior parte das organizações sociais, econômicas, culturais, que foram implantadas nos primeiros anos de imigração, visando a manutenção da coesão étnica, da cultura e seus corolários, mostramse hoje como auxiliares de vital importância para que estes "dekasseguis" consigam uma convivência menos traumática com o sistema japonês.

A par desta identidade, o capital, através do governo, consegue controlar o fluxo de entrada desses trabalhadores através da controvertida Lei de Imigração. O que atrai a força de trabalho é a alta remuneração oferecida pelas empresas japonesas, se comparada àquela do país de origem.

Para o capital, não há interesse em inserir esse contingente ao mercado de trabalho de forma vitalícia, como acontece com os trabalhadores japoneses. Ele deve estar disponível na fase de expansão da produção e mantido como reserva no momento de depressão, fazendo-o retornar ao país de origem ou ocupando-o em outros setores.

A sonegação da Previdência, o exagerado número de horas-extras dão ao trabalhador a fugaz sensação de serem novos ricos. Por outro lado, a "exportação de mão-de-obra" vem sendo uma atividade altamente rentável para os intermediários que repassam o lucro a uma infinidade de agentes recrutadores que, inocentemente ou interessados em ganho fácil, acabam por integrar-se à rede de vendedores de mão-de-obra.

As leis de imigração, por outro lado, são elaboradas e aprovadas de acordo com o interesse das grandes corporações, sendo o Estado um mero coadjuvante, visando apenas reduzir os conflitos entre capital e trabalho.

Constatou-se, através deste estudo, o processo de exploração da força de trabalho, onde as conquistas dos direitos trabalhistas não se aplicam a este contingente de trabalhadores. Há ocorrências de exaustão física, face ao trabalho em monótonas bancadas, onde os movimentos são repetidos centenas, milhares de vezes ao dia, podendo levar o trabalhador ao colapso cardíaco, hemiplegia, acidentes e moléstias profissionais.

Ao lado destes aspectos negativos, considerase que há condições de um entendimento entre países mais e menos desenvolvidos, desde que se atribua ao trabalho o seu devido peso, buscando a reciprocidade dos benefícios da previdência social, a fim de que os trabalhadores não retornem ao seu país de origem "sucateados". É também necessário disciplinar as ações das agências de viagens e de empregos, no sentido de se evitar a exploração dos trabalhadores e o uso de falsas promessas.

Observe-se que, aplicar a legislação trabalhista 
e as leis previdenciárias conquistadas a duras penas pelos trabalhadores dos países centrais já seria um passo significativo para a igualdade entre os homens.

\section{Balanço do fluxo migratório: papel das entidades nipo-brasileiras dos Governos brasileiro e japonês}

O movimento de trabalhadores brasileiros em direção ao Japão nestes dez anos foi bastante expressivo, ao se comparar com o fluxo inverso, de imigrantes japoneses para o Brasil, iniciado em 1908. Desta data até os nossos dias estima-se que 250.000 japoneses entraram no Brasil. O movimento inverso do Brasil para o Japão, segundo o Censo do Ministério de Relações Exteriores (março/96) contabilizou 170.000 pessoas, como foi referenciado em item anterior.

A par deste significativo fluxo, a indagação que se faz é sobre o papel exercido pelas entidades que estão inseridas na "colônia"nipo-brasileira, assim como dos governos dos países envolvidos.

As ações encetadas em ambos os países, oficiais ou de iniciativa privada, têm sido sempre "a posteriori" para remediar os efeitos negativos desse fluxo.

A atuação do capital é sempre precedente e criativa, conseguindo superar os eventuais obstáculos representados pelas medidas disciplinadoras das leis. Dois exemplos podem ilustrar estas questões:

O Artigo 206 do Decreto-Lei 2848 de 07.09.1940, do Código Penal Brasileiro preceituava que, "aquele que aliciar trabalhadores para fins de emigração estará sujeito à pena de detenção de um a três anos". Para contornar este artigo, as empresas do Japão recrutavam no Brasil, os japoneses radicados no Brasil, que estariam, simplesmente, retornando temporariamente ao seu país. À medida que escasseava a disponibilidade, iniciou-se o recrutamento de "nisseis"(primeira geração de imigrantes japoneses), infringindo o dispositivo legal em vigor. No Simpósio sobre Dekasseguis, realizado em 1991, em São Paulo, reivindicou-se a sua revogação.

No Japão, houve também uso de artifício, visando superar a situação de ilegalidade que se apresentava em que os "nisseis"não poderiam exercer atividades remuneradas naquele país. No entanto, a saída encontrada era embarcar como turista e prorrogar a permanência sob a forma de visita a parentes, por mais seis meses. Neste caso, trabalhava-se irregularmente, pois não lhe era permitido exercer atividade remunerada.

Estas dificuldades cessaram em junho de 1990, quando o governo japonês concedeu ao "nissei"o status de filho de japoneses no exterior, portanto, com direito de permanência de três anos e a possibilidade de exercer qualquer atividade, inclusive o trabalho remunerado.

Outra forma de burlar as leis é no tocante a contribuição junto à Previdência Social, que representa um encarecimento na folha de pagamento. Para contorná-lo, as empresas recorrem aos intermediários de mão-de-obra que, além de ilegais, simplesmente sonegam a contribuição patronal.

As associações nipo-brasileiras entenderam que o movimento desses trabalhadores ao Japão fosse um fenômeno transitório, com duração de poucos anos e com um contingente insignificante, preferindo assim ignorá-lo, deixando os riscos deste fluxo para o "dekassegui" e sua família. No entanto, o fluxo foi aumentando, a ponto de, com raras exceções, qualquer família "nikkei" ter algum parente no Japão como "dekassegui".

O Simpósio Sobre o Fenômeno Dekassegui, já referenciado, teve como resultado concreto a criação, em abril de 1992, do Centro de Informação e Orientação ao Dekassegui, como uma das atividades da Sociedade Brasileira de Cultura Japonesa - BUNKYO. Este Centro funcionou por seis meses, dando lugar ao Centro de Informação e Apoio ao Trabalhador no Exterior - CIATE -, uma sociedade civil sem finalidade de lucro, tendo no seu Conselho Deliberativo a participação da Sociedade Brasileira de Cultura Japonesa - BUNKYO, da Federação das Associações das Províncias do Japão no Brasil KENREN e da Beneficência Nipo-Brasileira - ENKYO, recebendo o apoio financeiro do governo japonês. Podese dizer que no Brasil é a entidade que centraliza as atividades de orientação e apoio aos "dekasseguis", em ação conjugada com os Centros de Assistência de Empregos para Nikkeis, localizados em Tóquio e Nagóia- no Japão, instalados, respectivamente, em agosto de 1991 e outubro de 1993.

Outra iniciativa brasileira foi a montagem do balcão SEBRAE, junto à filial do Banco do Brasil em Tóquio, no sentido de captar os recursos gerados pelos "dekasseguis" para transformá-los em aplicações financeiras, em projetos de investimento e atividades empresariais no Brasil. Algumas prefeituras têm se utilizado do SEBRAE, do SENAC, para proporcionar apoio aos nikkeis que pretendem investir no Brasil.

As entidades nipo-brasileiras têm ensaiado algumas ações para apoiar os que retornam ao Brasil. Dentre estas, temos a iniciativa da Universidade Estadual de Londrina - UEL, reunindo as Associações NipoBrasileiras do Norte do Paraná, para reintegrar os retornados. Este grupo de instituições realizou em outubro de 1995 um Simpósio Internacional Sobre Dekasseguis, abordando especificamente o seu Regresso, sua Reintegração e suas Perspectivas. As conclusões deste Simpósio estão subsidiando a criação de uma entidade que auxilie os trabalhadores que se dirigem ao Japão, tanto na saída do país quanto no seu retorno. Em São Paulo, também está havendo uma tímida iniciativa, junto aos que regressam ao país.

No Japão, sem dúvida, o Centro de Assistência de Empregos para Nikkeis de Tóquio e Nagóia, centraliza as ações envolvendo os brasileiros, peruanos, argentinos, bolivianos e paraguaios. Dentre as 630 Agências Públicas de apresentação de empregos, vinculados ao Ministério do Trabalho, que se distribuem por todo o território japonês, cerca de 30 contam com servidores temporários, bilingües, atendendo os 
brasileiros e outros "nikkeis" da América Latina que buscam empregos diretos nas empresas, sem a interferência dos "empreiteiros"ou intermediários.

Outra entidade que pode ser citada é o Serviço de Assessoria e Informação para os Trabalhadores Nikkeis (SAITRAN), ligado ao Ministério de Relações Exteriores do Japão, que tem prestado esclarecimentos através de ligações telefônicas.

O governo brasileiro, através da Embaixada e dos Consulados, vem instalando os Conselhos de Cidadãos, integrados por brasileiros e membros do corpo diplomático no Japão, para discutir e dar encaminhamento aos diversos problemas que vêm afetando os trabalhadores.

Ações de iniciativa particular têm também sido implementadas, em número significativo, porém são de caráter local e de duração efêmera. Algumas iniciativas vêm travestidas de caráter assistencial, mas sua verdadeira finalidade é atingir os trabalhadores brasileiros para fins comerciais.

Enfim, ao realizar o balanço deste movimento migratório para o Japão, é importante avaliar, ainda que esquematicamente, os aspectos positivos e negativos, para o indivíduo, para sua comunidade e para o país emissor.

Como aspecto positivo, sem dúvida alguma, constituiu-se uma solução imediata para milhares de pessoas atingidas pelo desemprego e pela recessão. Para outras, representou a oportunidade de aquisição de bens (sobretudo no setor imobiliário), veículos ou abertura de pequenas empresas. Essa migração propiciou também, a possibilidade de um conhecimento mais aprofundado da cultura japonesa, a oportunidade de aprender a língua dos seus pais e avós, o contato com parentes residentes naquele país. Representou, outrossim, um aperfeiçoamento profissional, com aprendizado de novos sistemas de produção.

Em contrapartida, muitas famílias conheceram a desagregação, crianças se desajustaram, pessoas foram acometidas de doenças, sofreram acidentes de trabalho, acidentes de trânsito, mortes. Outras foram contratadas para trabalhar em ocupações de alto risco, desgastantes e nem sempre condizentes com sua formação profissional.

Em termos de comunidade, ela se beneficiou com a injeção de recursos, com os novos empreendimentos, enriqueceu-se com a introdução de novas tecnologias. Entretanto, a saída de seus membros esvaziou o quadro associativo e diretivo das entidades nipo-brasileiras, desmotivando os que nela permaneceram. Representou também um esvaziamento nas atividades produtivas ligadas a agricultura, além da perda de técnicos e profissionais nos setores produtivos urbanos. O retorno dos trabalhadores, com recursos amealhados no exterior, inflacionou os preços de imóveis urbanos e rurais, inviabilizando muitas iniciativas locais.

Para o país, representou um ingresso significativo de divisas, muito maior do que qualquer produto brasileiro, contribuindo para a balança de pagamentos. Outro benefício foi o de receber trabalhadores com nova mentalidade, introduzindo novas tecnologias e procedimentos de trabalho.

Do ponto de vista negativo, verificou-se que parte da população em quem a sociedade investiu recursos consideráveis para a sua formação evadiu-se para o exterior, justamente no momento em que estavam aptos para comporem a mão-de-obra junto ao setor produtivo do país.

Um outro aspecto que não pode ser deixado de lado é a imagem desgastada do nipo-brasileiro, pelos empregadores brasileiros, que preferem contratar os não-descendentes de japoneses, com receio de que estes poderão trocar o seu emprego no Brasil pelo emprego no Japão.

Em suma, se apenas os ganhos (materiais) individuais dos "dekasseguis"que retornam ao país forem considerados, verifica-se que houve avanços significativos, porém, ao se analisar o processo migratório, globalmente, evidencia-se uma realidade em que as perdas são maiores do que os ganhos. No entanto, como os deslocamentos decorrem de decisões individuais, somente ao surgirem os problemas decorrentes deste fato é que a comunidade começa a buscar as alternativas para a resolução dos mesmos, de forma coletiva, como os que foram relatados neste item.

\section{Conclusões}

A questão migratória deve ser analisada sob todos os enfoques possíveis. Para tanto, mister se faz tratar esta questão como um todo dinâmico que envolve fatos como: quais as motivações para os deslocamentos? Que dificuldades foram encontradas pelos que se aventuram em sair do país em busca de melhores condições de vida? Qual o papel do Estado para recepcionar ou liberar pessoas que vão compor seu contingente de trabalhadores ? Como superar a situação de "marginalidade"em que se encontra o migrante em ambos os países ?

O fluxo migratório analisado privilegiou os trabalhadores brasileiros(descendentes de imigrantes japoneses) no Japão, enfatizando-se a motivação para a saída do seu país: a busca de melhoria nas condições de sobrevivência, representada pela alta remuneração a receber, apesar dos tipos de trabalho nãoespecializado que deverá executar, das horas extras, da desestruturação familiar, dos problemas de saúde, psicológicos, enfim, da sobrecarga de obrigações que terá de cumprir no exterior, somada ainda a uma vida à margem da sociedade receptora, que o quer apenas como um componente do setor produtivo.

Verificou-se ainda que os movimentos de população incorporam as características das sociedades vivenciadas temporalmente, isto é, as políticas migratórias estão ligadas às estratégias internacionais das grandes corporações e da política de desenvolvimento dos países, com mão-de-obra insuficiente para atender a demanda do seu sistema de produção. 
A busca ao "pote do ouro"no fim do arco-íris é realizada, principalmente, por adultos jovens, com maior capacidade para o trabalho, o que se revela extremamente injusto, pois estes não estarão auxiliando o seu país no esforço de desenvolvimento, porém num sistema de mercado concorrencial, a escolha recairá para os locais onde se remunera melhor, mesmo que seja em atividades diferentes daquela para o qual empregou seus anos de estudo. Enfim, os "dekasseguis" são homens do mundo, que se movimentam aos sabores das necessidades econômicas dos países, isto é, com a globalização do mercado de trabalho e a acentuada desigualdade regional que ora se verifica, tornam as migrações, predominantemente, temporárias e aos migrantes cabe o papel de trabalhadores que vivenciam um movimento pendular internacional.

ASARI, A.Y.; YOSHIOKA, R. Migration ultramarine. Brazilians workers in Japan. Semina: Ci.

Sociais/Humanas, Londrina, v. 17, n. 3, p. 237-245, Sep. 1996.

ABSTRACT: This study analyse migratory moving specifically, the flux of brazilians workers whose ascendacy is japanese, to Japan. This workers flux started at end of 80 decade and there are about 170.000 brazilians in Japan, like workers without specialization. The migratories moving area are influenced by economic-social-politic interests of both countries. The temporary worker's migration turn them "men of the world" who move according to the necessities of the manual work of the developed and underdeveloped countries.

KEY-WORDS: Migratory moving; brazilians workers; temporary migration.

\section{REFERÊNCIAS BIBLIOGRÁFICAS}

ASARI, A.Y.A. ... E eu só queria voltar ao Japão. Colonos japoneses de Assai. SãoPaulo: FFLCH-USP/

Departamento de Geografia. 1992 (Tese de Doutoramento)

CAMARA, M.R.G. Migrações internas: evolução teórica e algumas evidências empíricas para o caso brasileiro Revista Semina, Londrina, 9(2):101-110, 1988

CASTRO, M.L. O fenômeno dekassegui. Os trabalhadores nikkei brasileiros no Japão. São Paulo em Perspectiva 8(1):102-106, janeiro/março 1994

FUNDO DAS NAÇÕES UNIDAS PARA A POPULAÇÃO. 0 indivíduo e o Mundo: População, Migração e Desenvolvimento na década de 1990. Nova York. 1993

FUZII, E.O. Dekassegui, passaporte para uma experiência de vida. Londrina, Universidade Estadual de Londrina, 1991 (mimeo)

GEORGE, P. Geografia da População.5.ed. Rio de Janeiro, DIFEL, 1970

KLAGSBRUNN, V.H. Emigração e mercado de trabalho no Brasil: a emigração para os Estados Unidos, Japão e Portugal. s/d (mimeo)

KLINTOWITZ, J. Nossa gente lá fora. Revista VEJA. Ano 29, 03.04 .96

MARTINS, J.S. Não há terra para plantar neste verão.2.ed Petrópolis, Vozes, 1988

NINOMIYA, M (org.) Palestras e Exposições do Simpósio sobre o fenômeno chamado Dekassegui. São Paulo. Estação Liberdade:Sociedade de Cultura Japonesa.1992

ROSSINI, R.E. O retorno às origens ou a luta pela cidadania. O exemplo dos dekassseguis do Brasil em direção ao Japão. Revista da USP, São Paulo (27):24-31, setembro/novembro 1995

SALES, T. Brasil migrante, Brasil clandestino. São Paulo em Perspectiva. 8(1):107-15, janeiro/março 1994
SANTOS, M. Por uma Geografia Nova. 2.ed.São Paulo, HUCITEC, 1980

Espaço e sociedade. Petrópolis, Vozes, 1979

Metamorfoses do espaço habitado.3.ed. São Paulo: HUCITEC. 1994

SINGER, P.I. O papel do crescimento populacional no desenvolvimento econômico. 2.ed. São Paulo, HUCITEC. 1977

YAMOCHI, Y. Imigração japonesa: ontem e hoje. O exemplo dos japoneses da comunidade nikkei de Urai (PR). Nara, Japan, Tenrikyo Overseas Mission. Department.1992 (Dissertação de Mestrado-FFLCH-USP)

YOSHIOKA, R. Por que migramos do e para o Japão. São Paulo. Massao Ohno Ed. 1995. (Tese de Doutoramento apresentada a FFLCH-USP)

REVISTAS, JORNAIS, OUTRAS PUBLICAÇŌES:

CIATE, Centro de Informação e Apoio ao Trabalhador no Exterior. Boletim Mensal. São Paulo. 1993 a 1995

JORNAL DIÁRIO NIPPAK, São Paulo, 01.12.1993

JORNAL FOLHA DE LONDRINA. Uma aventura no Japão(...) Rumo ao Oriente.30- 01 a 04.02.1990

JORNAL FOLHA DE SÃO PAULO, Planeta em Movimento, 1820.07.1991

JORNAL NOTÍCIAS DO JAPÃO, São Paulo, 26/04 e 03/05/96

JORNAL O ESTADO DE SÃO PAULO. Japoneses voltam ao Japão,fugindo da crise no Brasil.13.04.1988

JORNAL PARANÁ SHIMBUM, Londrina, 12.04.1990

REVISTA VEJA, O grande êxodo. O povo da diáspora, São Paulo, 07.08.1990

Semina Ci. Sociais/Hum, v 17 n. 3, p. $237-245$ 